\title{
Implementasi Pembelajaran Mata Kuliah Wajib Umum Pendidikan Kewarganegaraan Berbasis Unity of Science
}

\author{
Bakti Fatwa Anbiya1, Abas Asyafah² \\ ${ }^{1}$ Fakultas Ilmu Tarbiyah dan Keguruan UIN Walisongo Semarang, Indonesia \\ 2Sekolah Pascasarjana Universitas Pendidikan Indonesia, Indonesia \\ 1baktifatwaanbiya@walisongo.ac.id
}

\begin{abstract}
ABSTRAK
Penelitian ini bertujuan untuk mendeskripsikan implemetasi pembelajaran Mata Kuliah Wajib Umum Pendidikan Kewarganegaraan dalam kerangka paradigma Unity Of Science di UIN Walisongo Semarang. Pendekatan dalam penelitian ini yakni pendekatan kualitatif dengan mengunakan metode analisis deskriptif. Teknik pengumpulan data adalah wawancara, observasi dan dokumentasi. Pendekatan Unity Of Science sebagai paradigma dalam pembelajaran Pendidikan Kewarganegaraan di UIN Walisongo Semarang memiliki karakteristik: humanisasi ilmu keislaman, spiritualisasi ilmu pengetahuan dan revitalisasi kearifan lokal yang terintegrasi melalui rencana pembelajaran semester (RPS) dan kegiatan pembelajaran mata kuliah Pendidikan Kewarganegaraan. Hasil penelitian menunjukkan bahwa pendekatan ini merupakan upaya semangat spritualisasi ilmu pengetahuan guna membentuk moderasi beragama dengan mengkontekstualisasi ayat-ayat Al-Quran dengan materi dan kegiatan pembelajaran Pendidikan Kewarganegaraan. Paradigma Unity Of Science memberikan makna kepada mahasiswa bahwa pembelajaran mata kuliah Pendidikan Kewarganegaraan sarat dengan nilai-nilai spiritual yang berhubungan dengan ajaran Islam dan menjadi modal utama dalam pembinaan warga negara yang moderat.
\end{abstract}

Kata kunci: Pendidikan Kewarganegaraan, Unity of Science, spiritualisasi ilmu pengetahuan

\section{ABSTRACT}

This study aims to describe the learning implementation of Citizenship Education as a mandatory general subjects in the framework of the Unity of Science paradigm at Islamic State University UIN Walisongo Semarang. This research used descriptive research method. The data collection techniques were interviews, observation and documentation. The Unity of Science paradigm in learning Citizenship Education at UIN Walisongo Semarang has the following characteristics; humanization of Islamic sciences, spiritualization of knowledge and revitalization of local wisdom integrated through the course syllabus and Citizenship Education learning activities. The results of this study indicate that this paradigm is a science spiritualization effort to create religious moderation by contextualizing the verses of the Qur'an with Civic Education materials and learning activities. The Unity of Science paradigm teaches the students that the Citizenship Education learning is coherent with spiritual values coming from Islamic teachings and is the main capital in fostering moderate citizenship.

Keywords: Citizenship Education, Unity of Science, spiritualization of science

This work is licensed under the Creative Commons Attribution-ShareAlike 4.0 International License. (C2020 by the author(s). 


\section{PENDAHULUAN}

Pembelajaran pada hakikatnya adalah upaya mengarahkan peserta didik dalam proses belajar agar mendapatkan apa yang diharapkan (Raehang, 2014). Tenaga pendidik berperan penting dalam menentukan keberhasilan capaian pembelajaran. Belajar merupakan perubahan penampilan atau tingkah laku, dengan runtutan kegiatan misalnya dengan mengamati, membaca, mendengarkan, serta meniru (Sadirman, 2003). Faktor keberhasilan suatu proses pembelajaran tidak bisa dilepaskan dari peranan guru atau dosen dalam meremuskan tujuan dan capaian pembelajaran serta penentuan pendekatan dalam proses pembelajaran. Beberapa faktor yang mempengaruhi keberhasilan pembelajaran di antaranya; teknik pembelajaran, kapasitas pembelajaran, tingkah laku pendekatan (manner of approach), pengaruh situasi dan kecenderungan (predisposition) (Matei \& Bogdan (2011).

Dalam pembelajaran, pendekatan yang digunakan sangat berperan dalam proses belajar mengajar. Selain memiliki peran dalam menarik perhatian mahasiswa, pendekatan pembelajaran memiliki peran dalam menyampaikan pesan yang akan disampaikan pada setiap mata pelajaran/mata kuliah. Penggunaan pendekatan pembelajaran menjadi salah satu faktor yang penting dalam tercapainya tujuan pembelajaran, begitu pula dalam proses pembelajaran Mata Kuliah Wajib Umum di Perguruan Tinggi. Pembelajaran Mata Kuliah Wajib Umum bertujuan untuk pembangunan karakter yang sesuai dengan Pancasila (Ristek Dikti, 2016).

Mata Kuliah Pendidikan Kewarganegaraan merupakan mata kuliah yang memberikan pedoman kepada setiap individu untuk menelaah, mengkaji, menganalisis dan memecahkan masalah-masalah bangsa dan negara dalam perspektif nilai-nilai Pancasila sebagai ideologi dan dasar negara Republik Indonesia. Sebagaimana tertuang dalam Undang-Undang RI No. 20 Tahun 2003 tentang Sisdiknas Pasal 31 ayat (1), "Pendidikan Kewarganegaraan dimaksudkan untuk membentuk peserta didik menjadi manusia yang memiliki rasa kebangsaan dan cinta tanah air." Bila diinterpretasi lebih jauh undang-undang ini mengamanatkan pembentukan individu Indonesia yang memiliki jiwa patriot dan berkomitmen pada Negara Kesatuan Republik Indonesia. Maka dari itu negara bertanggung jawab mempersiapkan generasi muda yang berwawasan kebangsaan dan rasa cinta tanah air berdasarkan Pancasila, Undang-Undang Dasar 1945 dan berkomitmen kepada Negara Kesatuan Republik Indonesia. Pendidikan Kewarganegaran secara holistik memiliki tujuan agar setiap warga negara muda (young citizen) memiliki rasa cinta tanah air dan dan rasa kebangsaan. Pelajaran Pendidikan Kewarganegaraan secara sadar dan terencana menjadikan peserta didik belajar kehidupan demokrasi secara utuh yang mencakup belajar dalam iklim, melalui proses, serta belajar membangun demokrasi (Winata Putra, 2014).

Ancaman yang dihadapi bangsa Indonesia dewasa ini bersifat non-militer. Ancaman non-militer diartikan sebagai ancaman yang menggunakan faktor-faktor non militer yang membahayakan kedaulatan negara serta keselamatan bangsa (Indrawan, 2015) dan memiliki dimensi ideologi, politik, ekonomi, sosial budaya, teknologi informasi, dan keselamatan umum (Indrawan, 2016).

Salah satu ancaman non-militer adalah idelogi radikalisme dan intoleranisme. Hal tersebut menjadi ancaman serius yang memerlukan penanganan yang serius 
pula. Kekhawatiran akan ancaman radikalisme di dunia pendidikan bukanlah hal yang berlebihan. Selaras dengan data yang dirilis Badan Nasional Penanggulangan Terorisme (BNPT) pada tahun 2018, terdapat tujuh Perguruan Tinggi Negeri yang terpapar radikalisme (BNPT, 2019). Pada tahun yang sama pula Badan Intelijen Negara (BIN) merilis data bahwa 39\% mahasiswa di 15 provinsi terpapar paham radikalisme (Setara Institute, 2019).

Alvara Research Center (2017) merilis hasil survei yang mengindikasikan kecenderungan pemahaman dan sikap yang intoleran dan radikal pada mahasiswa. Hal ini ditunjukkan dengan cukup besarnya jumlah mahasiswa yang; (a) tidak mendukung pemimpin non-muslim (29,5\%); (b) mahasiswa yang setuju dengan negara Islam (23,5\%); dan (c) mahasiswa yang setuju dengan khilafah (17,8\%). Pada tahun 2016, LIPI menyebutkan bahwa gerakan radikal menyasar kampus-kampus melalui rekrutmen kader yang memanfaatkan forum-forum diskusi dan organisasi mahasiswa di kampus (Setara Institute, 2019).

Berdasarkan data tersebut, terdapat persoalan serius yang harus ditangani oleh kampus-kampus di Indonesia dalam menangkal gerakan radikalisme. Universitas Islam Negeri Walisongo Semarang merupakan salah satu Universitas Islam Negeri yang memiliki cita-cita sebagai pewaris para walisongo dalam meyebarkan Islam Wasatiyah (moderat), hadir dengan visi menjadi Universitas Islam riset terdepan berbasis kesatuan ilmu (unity of science).

Kesatuan ilmu menjadi suatu pendekatan dalam memahami konteks ilmu pengetahuan yang tidak parsial dengan proses non dikotomis antara ilmu barat dan ilmu agama yang bersifat humanis (Al Faruqi, 2005). Pendekatan kesatuan ilmu ini digunakan dalam proses pembelajaran mata kuliah Pendidikan Kewarganegaran di Universitas Islam Negeri Walisongo Semarang. Di dalamnya dijelaskan bahwa materi Pendidikan Kewarganegaran yang bercorak demokrasi Barat dapat sejalan dengan islamisasi ilmu pengetahuan melalui semangat nilai-nilai Islam humanis.

Berdasarkan permasalahan yang telah diuraikan di atas, penelitian ini bertujuan untuk mendeskripsikan implentasi pembelajaran Mata Kuliah Wajib Umum (MKWU) Pendidikan Kewarganegaraan berbasis kesatuan ilmu ditinjau dari perencanaan dan pelaksanaan pembelajaran Mata Kuliah Pendidikan Kewarganegaraan dalam upaya membentuk warga negara yang moderat.

\section{METODE PENELITIAN}

Penelitian ini menggunakan pendekatan kualitatif dengan metode deskriptif analisis. Karakteristik penelitian adalah natural setting, yaitu pengumpulan data secara alami (Creswell, 2013). Adapun pengumpulan data dilakukan dengan prosedur wawancara, observasi, dan dokumentasi. Wawancara dilakukan kepada dosen dan mahasiswa Mata Kuliah Wajib Umum (MKWU) Pendidikan Kewarganegaraan. Observasi dilakukan pada saat pembelajaran MKWU Pendidikan Kewarganegaraan berlangsung, sedangkan analisis data dilakukan setalah data umum terkumpul dengan pernyataan yang bersifat umum dan informasi dari para partisipan (Creswell, 2013). Selanjutnya penelitian ini menggunakan analisis data dengan menggunakan model interaktif (Miles dan Huberman 2014), yaitu reduksi, penyajian, dan pengambilan keputusan. 
Subjek pertama adalah dua dosen pengampu MKWU Pendidikan Kewarganegaraan yang mengajar pada enam program studi di Fakultas Ilmu Tarbiyah dan Keguruan, UIN Walisongo Semarang. Penetapan ini didasarkan atas pertimbangan bahwa kedua dosen tersebut memiliki kualifikasi magister Pendidikan Kewarganegaraan dan Studi Islam. Subjek kedua adalah mahasiswa Fakultas Ilmu Tarbiyah dan Keguruan UIN Walisongo Semarang yang mengambil MKWU Pendidikan Kewarganegaraan (UIN-6026) pada semester genap tahun akademik 2018-2019. Mereka berjumlah enam orang yang terdiri dari tiga laki-laki dan tiga perempuan dari enam rombongan belajar yang berbeda yang mewakili enam prodi, di antaranya Prodi Pendidikan Agama Islam, Prodi Pendidikan Bahasa Inggris, Prodi Pendidikan Guru Madrasah Ibtidaiyah, Prodi Pendidikan Anak Usia Dini, Prodi Pendidikan Bahasa Arab dan Prodi Manajemen Pendidikan Islam. Adapun pertimbangan memilih fokus di Fakultas Ilmu Tarbiyah dan Keguruan UIN Walisongo Semarang karena merupakan fakultas dengan jumlah mahasiswa terbanyak yaitu 1.740 Mahasiswa yang terdiri atas angkatan 2016, 2017, dan 2018.

\section{HASIL PENELITIAN}

Dalam hasil penelitian ini dibahas perencanaan dan implementasi pembelajaran MKWU Pendidikan Kewarganegaraan berbasis kesatuan ilmu. Secara yuridis pelaksanaan MKWU Pendidikan Kewarganegaraan di Universitas Islam Negeri Walisongo Semarang terdapat pada Undang-Undang No. 12 Tahun 2012 tentang Pendidikan Tinggi Pasal (35) ayat 3 mengenai kurikulum. UU ini menyatakan bahwa kurikulum Pendidikan Tinggi dikembangkan oleh setiap perguruan tinggi dengan mengacu pada Permenristekdikti No. 44 Tahun 2015 tentang Standar Nasional Pendidikan Tinggi (2015) yang mewajibkan memuat Mata Kuliah Agama, Pancasila, Pendidikan Kewarganegraan, dan Bahasa Indonesia. Kedua regulasi tersebut dipertegas dengan dikeluarkannya Surat Keputusan Rektor Universitas Islam Negeri Walisongo No. 407 Tahun 2017 tentang Penjaminan Mutu Internal Universitas Islam Negeri Walisongo BAB III Bagian A Standar Pendidikan UIN Walisongo Poin (3) yang berbunyi "Universitas memastikan kedalaman dan keluasan materi pembelajaran dengan memanfaatkan hasil-hasil penelitian dan pengabdian kepada masyarakat yang berbasis kesatuan ilmu (Unity Of Science)". Poin (4) menyatakan "Kurikulum yang digunakan adalah Kurikulum Berbasis Kompetensi (KBK) serta mengacu kepada Standar Nasional Perguruan Tinggi (SNPT) dan Kerangka Kualifikasi Nasional Indonesia (KKNI) menggunakan paradigma kesatuan ilmu pengetahuan".

Adapun karakteristik dari paradigma kesatuan ilmu dalam penyusunan Rencana Pembelajaran Semester (RPS), antara lain: pertama, humanisasi ilmu keislaman. Hal tersebut dapat diartikan sebagai proses menkonstruksi kembali rumpun ilmu keislaman sebagai upaya memadupadankan nilai-nilai universal Islam dengan ilmu pengetahuan modern. Kedua, spiritualisasi ilmu pengetahuan dengan memberikan pijakan nilai-nilai ilahiyah (wahyu) terhadap ilmu-ilmu sekuler sebagai upaya membangun ilmu pengetahuan baru yang didasarkan pada kesatuan ilmu yang bersumber pada ayat-ayat Allah SWT baik yang didapat melalui nabi, eksplorasi akal, maupun eksplorasi alam. Ketiga, revitalisasi kearifan lokal adalah 
upaya menggali nilai-nilai kearifan bangsa Indonesia sebagai upaya penguatan karakter bangsa. Konsep kesatuan ilmu merupakan upaya membangun harmonisasi ilmu pengetahuan yang terdikotomis (Muhaya, 2015) sehingga, berdasarkan perangkat yuridis di atas, berdampak pada penyusunan Rencana Pembelajaran Semester (RPS) mata kuliah Pendidikan Kewarganegaraan yang mengharuskan berbasis kepada kesatuan ilmu. Di dalamnya terdapat integrasi nilai-nilai keislaman, baik itu ayatisasi maupun tradisi serta kearifan lokal.

Berdasarkan analisis komponen Rencana Pembelajaran Semester (RPS) yang disusun oleh Konsorsium Dosen Mata Kuliah Pendidikan Kewarganegaraan Universitas Islam Negeri Walisongo Semarang diketahui bahwa bobot mata kuliah Pendidikan Kewarganegaraan sebesar 2 SKS dengan 16 kali pertemuan tatap muka, termasuk di dalamnya Ujian Tengah Semester dan Ujian Akhir Semester. Komponen Rencana Pembelajaran Semester (RPS) dapat dilihat pada tabel berikut.

\section{Tabel 1. Komponen Rencana Pembelajaran Semester (RPS)}

\begin{tabular}{lll}
\hline No. & Komponen & Sub komponen \\
\hline 1. & Identitas & A. Nama Mata Kuliah \\
& & B. No. Revisi Dokumen \\
& & C. Jumlah Halaman \\
& & D. Kode Mata kuliah \\
& & E. Lembar Pengesahan \\
& & F. Capaian Mata Kuliah \\
& & G. Deskripsi Mata Kuliah \\
\hline 2. & Daftar Referensi & Memuat buku, jurnal, dan ensiklopedia yang relevan \\
& & dengan mata kuliah Pendidikan Kewarganegaraan \\
\hline 3. & Rincian Konten & A. Rincian pertemuan (pertemuan ke...) memuat topik \\
& Inti RPS & B. Kerkuliahan \\
& & C. Indikator \\
& & D. Penilaian akhir pertemuan \\
& E. Bahan kajian/materi perkuliahan \\
& F. Metode \\
& G. Konten kesatuan ilmu (mengkoherensikan materi pem- \\
& Helajaran PKn dengan nilai-nilai Islam dan kearifan lokal) \\
& I. Pengalaman belajar \\
& & I. Alokasi waktu \\
\hline
\end{tabular}

Sumber: Rencana Pembelajaran Semester (RPS) Mata Kuliah Pendidikan Kewarganegaraan Konsorsium Mata Kuliah Pendidikan Kewarganegaraan, 2019

Berdasarkan Tabel 1 dapat dianalisis bahwa konten kesatuan ilmu tertuang secara tegas dalam komponen Rencana Pembelajaran Semester (RPS). Dengan demikian para dosen pengampu MKWU Pendidikan Kewarganegaraan di UIN Walisongo harus mampu menghubungkan materi Pendidikan Kewarganegaraan dengan konteks pendekatan kesatuan ilmu. Berikut tabel integrasi MKWU Pendidikan Kewarganegraan dengan kesatuan ilmu. 
Tabel 2. Integrasi Materi Pendidikan Kewarganegaraan dengan Kesatuan Ilmu (Unity Of Scince)

\begin{tabular}{|c|c|c|}
\hline No & Konten Materi PKn & Konten Kesatuan Ilmu (Unity Of Scince) \\
\hline 1 & Identitas Nasional & Berkoherensi dengan Q.S Al-Hujurat Ayat 13 \\
\hline 2 & Integrasi Nasional & Berkoherensi dari Surat Ali-Imron Ayat 103 dan 105 \\
\hline 3 & $\begin{array}{l}\text { Negara dan UUD } \\
\text { NRI } 1945\end{array}$ & $\begin{array}{l}\text { 1. Berkoherensi dengan sirah Nabi dalam } \\
\text { membentuk negara Madinah (Piagam Madinah) } \\
\text { berdasarkan kesepakan dan kompromi } \\
\text { 2. Penguatan terhadap nilai-nilai kebersamaan dan } \\
\text { ketaatan kepada kesepakatan yang dibuat secara } \\
\text { perwakilan (pemimpin) berlandaskan Q.S. 4:59 }\end{array}$ \\
\hline 4 & $\begin{array}{l}\text { Hak dan Kewajiban } \\
\text { Warga Negara }\end{array}$ & $\begin{array}{l}\text { Berkoherensi dengan perintah Allah SWT dalam Al- } \\
\text { Quran surat Al-Baqoroh ayat } 188 \text {. }\end{array}$ \\
\hline 5 & $\begin{array}{l}\text { Demokrasi } \\
\text { Indonesia }\end{array}$ & Fatwa-Fatwa Ulama Kontemporer tentang demokrasi \\
\hline 6 & $\begin{array}{l}\text { Penegakan Hukum } \\
\text { dan Hak Asasi } \\
\text { Manusia }\end{array}$ & $\begin{array}{l}\text { Berkoherensi dengan Surat An-Nisa Ayat } 58 \text { dan } 135 \\
\text { agar menegakkan hukum yang berkeadilan }\end{array}$ \\
\hline 7 & $\begin{array}{l}\text { Wawasan } \\
\text { Nusantara dan } \\
\text { Ketahanan Nasional }\end{array}$ & $\begin{array}{l}\text { Berkoherensi dengan perintah Allah SWT dalam } \\
\text { menjaga alam dari kerusakan dalam surat Al-A'raf } \\
\text { ayat } 56-58\end{array}$ \\
\hline
\end{tabular}

Sumber: Rencana Pembelajaran Semester (RPS) Mata Kuliah Pendidikan Kewarganegaraan Konsorsium Mata Kuliah Pendidikan Kewarganegaraan, (2019)

Berdasarkan tabel di atas dapat dianalisis lebih jauh bahwa para dosen pengampu MKWU Pendidikan Kewarganegaraan dalam menyusun RPS Pendidikan Kewarganegaraan berupaya untuk menganalisis materi Pendidikan Kewarganegaraan dengan metode ayatisasi. Hal ini berguna untuk mencari koherensi konteks materi MKWU Pendidikan Kewarganegaraan secara tematik dengan ayat Al Qur'an yang dalam istilah Al Faruqi menyebutnya sebagai Islamisasi ilmu pengetahuan (Abdussamad, 2015). Akan tetapi proses ayatisasi tersebut rentan cacat metodologis apabila para pengampu mata kuliah Pendidikan Kewarganegaraan lemah secara epistemologis. Hal tersebut disebabkan karena Pendidikan Kewarganegaraan maupun studi yang relevan dalam konteks ini memerlukan metode transdisiplin dan kolaboratif antara pengampu matakuliah Pendidikan Kewarganegaraan dengan pengampu mata kuliah Studi Islam dalam merumuskan RPS MKWU Pendidikan Kewarganegaraan berbasis kesatuan ilmu.

\section{Implementasi Pembelajaran Pendidikan Kewarganegaraan Berbasis Kesatuan Ilmu}

Implementasi dalam bentuk kegiatan pembelajaran diperlukan setelah menyusun RPS. Berdasarkan hasil pengamatan dan wawancara, ditemukan beberapa poin pokok pembelajaran mata kuliah Pendidikan Kewarganegaraan berbasis Kesatuan Ilmu, di antaranya adalah pendekatan pembelajaran. Pendekatan didefinisikan sebagai titik tolak terhadap proses pembelajaran yang bersifat umum, 
di dalamnya mewadahi, mengispirasi, menguatkan serta mendasari metode dengan cakupan teoritis tertentu.

Berdasarkan hasil wawancara dengan mahasiwa Fakultas Ilmu Tarbiyah dan Keguruan UIN Walisongo Semarang yang mengikuti perkuliahan Pendidikan Kewarganegaraan ditemukan pernyataan yang menarik. Mereka mengasumsikan bahwa perkuliahan Pendidikan Kewarganegaraan membosankan, konten hafalan, dan hanya sebagai mata kuliah sampingan. Namun tidak demikian dengan perkuliahan Pendidikan Kewarganegaraan di Fakultas Tarbiyah Ilmu Keguruan UIN Walisongo Semarang, di mana proses pembelajaran berpusat pada mahasiswa.

Berdasarkan hasil pengamatan dan wawancara peneliti dengan dosen pengampu MKWU Pendidikan Kewarganegaraan di Fakultas Ilmu Tarbiyah dan Keguruan UIN Walisongo Semarang, dapat dianalisa bahwa setidaknya setiap dosen mengajar menggunakan pendekatan yang variatif dalam proses perkuliahan. Hal tersebut berkoherensi dengan hasil penelitian terdahulu yang menemukan bahwa terdapat hubungan antara pendekatan pembelajaran dan pembelajaran. Hasil temuan tersebut menekankan bahwa penggunaan metode multiarah dalam pembelajaran berdampak bagus (Aflalo, \& Gabay (2013).

Penelitian ini juga melihat bahwa terdapat dua pendekatan dalam proses pembelajaran MKWU Pendidikan Kewarganegaraan di Fakutas Ilmu Tarbiyah dan Keguruan UIN Walisongo Semarang; pertama, pendekatan kontekstual. Pendekatan kontekstual diartikan sebagai proses yang melibatkan para siswa yang dapat membantu mereka menghubungkan pembelajaran dengan kehidupan nyata (Jhonson, 2002). Hal tersebut dapat diamati dalam proses kegiatan pembelajaran yang berlangsung di mana dosen pengampu mata kuliah Pendidikan Kewarganegaraan mengajak kunjungan ke komunitas-komunitas agama dalam konteks merawat kerukunan agama dalam materi Integrasi Nasional dengan konten kesatuan ilmu yang relevan dengan menyampaikan perintah agama untuk hidup berdampingan dan saling menghormati.

Kedua, pendekatan konstruktivisme. Berdasarkan hasil pengamatan, dosen pengampu mata kuliah Pendidikan Kewarganegaraan mengajak para mahasiswa untuk mengkonstruksi pengetahuan antara bekal pengetahuan awal yang dimiliki oleh mahasiswa dan pengalaman belajar. Hal tersebut berguna untuk menghasilkan pengetahuan baru yang sesuai dengan asumsi konstruktivistik bahwa belajar adalah kegiatan konstruksi terus menerus dan merevisi pengetahuan yang sebelumnya (Slavin, 1994). Dalam pendekatan konstruktivistik dosen pengampu mata kuliah Pendidikan Kewarganegaraan di FITK UIN Walisongo Semarang menggunakan model Project Citizen. Hal tersebut dilakukan karena sesuai dengan kebutuhan mahasiswa yang dituntut untuk dapat mengkonstruksi ilmu dengan dunia nyata (Sumarsih, 2009) serta melatih mahasiswa untuk berorintasi berfikir kritis, kreatif dan dapat memecahkan masalah (Budimansyah, 2009).

Pendekatan konstruktivistik dengan model project citizen dipadukan dengan konten materi Pendidikan Kewarganegaraan seperti tema Negara dan UUD NRI 1945 dipadukan dengan konten kesatuan ilmu melalui konsep negara dalam pandangan Islam. Upaya tersebut berguna memberikan penjelasan komprehensif yang terkait dengan konsepsi negara modern dan konteks negara dalam agama. 


\section{Kesatuan Ilmu dalam Pembelajaran Pendidikan Kewarganegaraan}

Kesatuan ilmu merupakan harmonisasi ilmu pengetahuan dengan integrasi dan interkoneksi antara ilmu Barat yang sekuler dan ilmu-ilmu keislaman yang berbasis wahyu. Paradigma kesatuan ilmu merupakan upaya untuk saling menghubungkan ilmu pengetahuan dan menembus sekat-sekat dikotomis ilmu pengetahuan (Abdullah (2006). Berdasarkan hasil pengamatan peneliti, ada tiga karakteristik kesatuan ilmu dalam proses pembelajaran Pendidikan Kewarganegaraan. Pertama, humanisasi ilmu keislaman. Dalam konteks ini peneliti belum menemukan secara eksplisit akan tetapi pada pengamatan proses pembelajaran Pendidikan Kewarganegaraan pada dosen yang berlatar belakang pendidikan magister studi islam, latar belakang keilmuan dosen yang bersangkutan mendominasi proses interkoneksi ilmu pengetahuan (Abdullah, 2006). Dosen tersebut mampu mengkorelasikan nilai-nilai Islam dalam konteks konten materi Pendidikan Kewarganegaraan. Misalnya dalam menjelaskan pemahaman agama yang moderat dalam konteks ke-Indonesia-an yang majemuk. Hal tersebut merupakan tindakan preventif karena akar radikalisme adalah pemahaman agama yang keliru (Saifudin, 2019). Kedua, spiritualisasi ilmu pengetahuan, berdasarkan hasil pengamatan proses pembelajaran dan telaah dokumen RPS peneliti menemukan upaya pengampu dosen Pendidikan Kewarganegaraan menghubungkan materi-materi Pendidikan Kewarganegaraan yang bercorak sekuler ke dalam nilai-nilai spiritual Islam. Misalnya, dalam konteks hak dan kewajiban warga negara selaras dengan perintah Islam untuk taat kepada pemimpin (QS. An Nisa 59). Materi Integrasi Nasional selaras dengan perintah larangan bercerai-berai (QS. Ali Imron 103). Ketiga, revitalisasi kearifan lokal dalam upaya menggali nilai-nilai kearifan bangsa Indonesia sebagai upaya penguatan karakter bangsa yang tertuang dalam penugasan perkuliahan dengan model project citizen. Hal tersebut dilakukan sebagai upaya dalam mengembangkan pengetahuan, kecakapan, dan watak kewarganegaraan yang demokratis (Budimansyah, 2009).

\section{SIMPULAN}

Proses pembelajaran MKWU Pendidikan Kewarganegaraan berbasis kesatuan ilmu memiliki peranan yang penting dalam membentuk sikap moderat mahasiswa dalam beragama. Pemilihan pendekatan dan model pembelajaran yang tepat, yaitu secara kontekstual dan konstruktivistik, telah menjadikan pembelajaran Pendidikan Kewarganegaraan di Fakultas Ilmu Tarbiyah dan Keguruan UIN Walisongo Semarang lebih bermakna pada mahasiswa. Hal tersebut bertujuan agar para mahasiswa mampu berfikir kritis, kreatif dan mampu memecahkan masalah. Namun terdapat kelemahan dalam penyusunan RPS MKWU Pendidikan Kewarganegaraan karena keterbatasan team teaching yang terdiri dari dosen Pendidikan Kewarganegaraan dan dosen Studi Islam. Berdasarkan hal tersebut, peneliti menyarankan agar dilakukan studi lanjut mengenai Pendidikan Kewarganegaraan dan konsep kesatuan ilmu dalam kerangka materi, model pembelajaran, serta pengaruhnya.

\section{REFERENSI}

Abdullah, A. (2006). Islamic Studies di Perguruan Tinggi: Pendekatan Integratif- 
Interkonektif. Yogyakarta: Pustaka Pelajar.

Abdussamad. (2015). Kesatuan Ilmu dalam Bingkai Dalam Pemikiran Pendidikan Islam Prespektif Ismail Al Faruqi. Islamuna Jurnal Studi Islam, 2(2), 287-300.

Aflalo, E \& Gabay, E. (2013). Learning Approach and Learning: Exploring a New Techologycal Learning System. International Jurnal Scolarship of Teaching $\mathcal{E}$ Learning, 7(1), 1-19.

Al Faruqi, I. R. (2005). Islamisai Pengetahuan (3rd ed.). Bandung: Pustaka.

Budimansyah, D. (2009). Inovasi Pembelajaran Project Citizen. Bandung: Pendidikan Kewarganegraan SPS UPI.

Craciun Bucur, Matei \& Bogdan, D. S. (2011). Knowladge Management. The Importence Learning Theory. Jurnal Of Knowladge Management Economics and Information Tehnology, 7(7), 1-8.

Creswell, J. W. (2013). Reaseach Design, Pendekatan Kualitatif, Kuantitatif Dan Mexed. Yogyakarta: Pustaka Pelajar.

Indrawan, J. (2015). Studi Strategis dan Keamanan. Jakarta: Nadia Pustaka.

Indrawan, J. (2016). Ancaman Non - Militer Terhadap Kemana Nasional Di Papua. UNPAR Jurnal Ilmiah Hubungan Internasional, 12(2), 65-78.

Jhonson. E.B. (2002). Contextual Teaching E Learning, What it is an way $i$ 'ts here to stay. California: Crowin Press, Inc.

Konsorsium Matakuliah Pendidikan Kewarganegaraan. (2019). Rencana Pembelajaran Semester (RPS) Matakuliah Pendidikan Kewarganegaraan. Semarang: UIN Walisongo Semarang.

Miles, M.B, Huberman, A. M, \& Saldana, J. (2014). Qualitative Data Analysis, Method Sourcebook, Edition 3. USA: Sage.

Muhaya, A. (2015). Unity Of Sciences According To Al -Ghazali. Walisongo: Jurnal Penelitian Sosial Keagamaan, 23(2), 311. https:// doi.org/10.21580/ws.23.2.281

Permenristekdikti No. 44 Tahun 2015 Tentang Standar Nasional Pendidikan Tinggi. (2015). Jakarta: Setneg RI.

Raehang. (2014). Pembeljaran Aktif Sebagai Induk Pembelaran Koopratif. Jurnal Al Ta'dib, 7(1), 149-167.

Ristek Dikti. (2016). Pendidikan Kewarganegraan Cetakan 1. Jakarta: Direktorat Jendral Pembelajaran Dan Kemahasiswaan Kementerian Riset Dan Pendidikan Tinggi Republik Indonesia.

Sadirman. (2003). Interaksi dan Motivasi Belajar. Jakarta: Jaya Grafindo Persada.

Saifudin, L. . (2019). Moderasi Beragama. Jakarta: Badan Litbang dan Diklat Kementerian Agama RI.

Setara Institute. (2019). Wacana Dan gerakan Keagaman di kalangan Mahasiswa: Memetakan Ancaman atas Negara Pancasila di Perguruan Tinggi Negeri. Jakarta: Setara Institute.

Slavin. (1994). Educational Pcycology Theory. Boston: By Allyn and Bacon.

Sumarsih. (2009). Implementasi Teori Pembelajaran Kontruktivistik Dalam Matakuliah Dasar Bisnis. Jurnal Pendidikan Akutansi Indonesia, 8(1), 54-62.

Surat Keputusan Rektor Universiats Islam Negeri Walisongo No. 407 Tentang Penjaminan Mutu Internal Universitas Islam Negeri Walisongo. (n.d.).

Undang- Undang RI No.20 Tahun 2003 Tentang Sisdiknas. (2006). Bandung: Fermana. 
Undang - Undang No. 12 Tahun 2012 Tentang Pendidikan Tinggi. (n.d.).

Winata Putra, U. (2014). Pendidikan Kewarganegaraan Dalam Prespektif Internasional. Jurnal ACTA Civicus, 1(1), 1-15. 